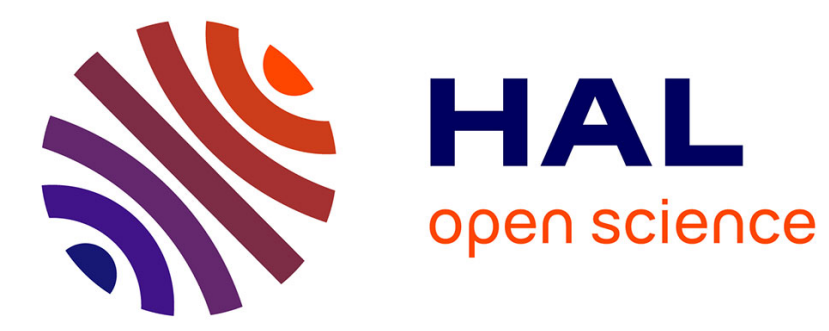

\title{
Deposition of MoO3 Films from a Volatile Molybdenyl Complex
}

\author{
B. Ballarin, E. Brescacin, G. Rizzi, E. Tondello
}

\section{To cite this version:}

B. Ballarin, E. Brescacin, G. Rizzi, E. Tondello. Deposition of MoO3 Films from a Volatile Molybdenyl Complex. Journal de Physique IV Proceedings, 1995, 05 (C5), pp.C5-509-C5-516. 10.1051/jphyscol:1995559 . jpa-00253921

\section{HAL Id: jpa-00253921 https://hal.science/jpa-00253921}

Submitted on 1 Jan 1995

HAL is a multi-disciplinary open access archive for the deposit and dissemination of scientific research documents, whether they are published or not. The documents may come from teaching and research institutions in France or abroad, or from public or private research centers.
L'archive ouverte pluridisciplinaire HAL, est destinée au dépôt et à la diffusion de documents scientifiques de niveau recherche, publiés ou non, émanant des établissements d'enseignement et de recherche français ou étrangers, des laboratoires publics ou privés. 


\title{
Deposition of $\mathrm{MoO}_{3}$ Films from a Volatile Molybdenyl Complex
}

\author{
B. Ballarin, E. Brescacin, G.A. Rizzi and E. Tondello
}

Centro di Studi sulla Stabilità e Reattività dei Composti di Coordinazione del CNR, Dipartimento di Chimica Inorganica Metallorganica ed Analitica, Via Marzolo 1, Università di Padova, 35141 Padova, Italy

\begin{abstract}
A volatile molybdenyl complex was used as precursor for MOCVD of $\mathrm{MoO}_{3}$ films. Decomposition paths were investigated by thermal analysis. Good quality films were obtained on different substrates and characterized by XPS, UV-Vis, XRD and SEM analyses. The different electronic properties of the various films on different substrates were studied by photoemission experiments and compared with respect to the $\mathrm{MoO}_{3}$ single crystal.
\end{abstract}

\section{INTRODUCTION}

Metal Organic Chemical Vapour Deposition (MOCVD) of $\mathrm{MoO}_{3}$ films is usually performed using $\mathrm{Mo}(\mathrm{CO})_{6}$ as precursor [1]. In this way, a metallic Mo film is obtained, which can be further oxidized by heating in oxygen. Molybdenum Hexacarbonyl is commercially available, stable and can be easily handled. Nevertheless, the obtained metallic films are usually affected by carbon contamination mainly caused by the presence of metal-carbon bonds in the precursor [2]. Other precursors like $\mathrm{MoF}_{6}, \mathrm{MoCl}_{5}$ or $\left(\eta^{6}-\mathrm{C}_{6} \mathrm{H}_{6}\right) \mathrm{Mo}(\mathrm{CO})_{3}$ may be used to obtain pure metallic films, but the required higher deposition temperature causes interdiffusion problems on substrates like Si [2].

Many transition metals like $\mathrm{Ti}, \mathrm{Cr}, \mathrm{V}$ and $\mathrm{Mo}$ form complexes of the type $\mathrm{M}(\mathrm{O})_{\mathrm{x}}(\mathrm{L})_{\mathrm{y}}$ where $\mathrm{L}$ can be a $\beta$-diketonate ligand. These compounds do not contain any metal-carbon bond so that only metal-oxygen double and single bonds are present in the coordination sphere. Therefore, this type of compounds can be suitable for the deposition of metal oxides in high oxidation state. In the case of Molybdenum several

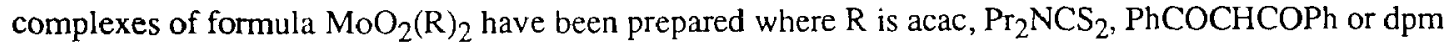
[3]. Only the complex with the dipivaloyl-methanato (Hdpm, 2,2,6,6 tetramethyl-3,5-heptanedione) ligand shows a sufficient volatility and stability to be used as precursor for $\mathrm{MOCVD}$ deposition of $\mathrm{MoO}_{3}$. Moreover, it is easily prepared and may be handled in air. In the solid state, it is stable for several weeks, provided prolonged light exposure is avoided. The presence of two metal-oxygen double bonds makes 
this complex a perfect candidate for the deposition of already oxidized Mo species so that possible interdiffusion into substrates like Si can be prevented [4]. In this case, a very low degree of carbon contamination in the films is expected since no direct metal-carbon bonds are contained in the complex.

We performed $\mathrm{MoO}_{3}$ films deposition in a cold wall reactor on polycrystalline $\mathrm{Pt}$ and $\mathrm{Ti}, \mathrm{Si}(100)$, stainless steel and $\mathrm{SiO}_{2}$ as substrates. All films were characterized by XPS while the effect of the substrate on crystallinity, morphology and electronic properties was investigated through XRD, SEM and UPS spectroscopy. In addition, a comparison of the XPS and UPS data obtained from a $\mathrm{MoO}_{3}$ single crystal is reported.

\section{EXPERIMENTAL}

\section{Synthesis of $\mathrm{MoO}_{2}(\mathrm{dpm})_{2}$}

Concentrated $\mathrm{HNO}_{3}$ is added dropwise to a $25 \mathrm{ml}(1: 1)$ ethanol - water solution of $\left(\mathrm{NH}_{4}\right)_{6} \mathrm{Mo}_{7} \mathrm{O}_{24} \cdot 4 \mathrm{H}_{2} \mathrm{O}$ $(0.5 \mathrm{mmol})$ until complete dissolution of molybdic acid occurs. The resulting yellow solution is mixed with $1.5 \mathrm{ml}(7.2 \mathrm{mmol})$ of 2,2,6,6 tetramethyl-3,5-heptanedione under vigorous stirring. The insoluble organic phase turns deep yellow after 30 mins and is extracted with benzene. After solvent and excess ligand evaporation a yellow solid is obtained. All procedures are carried out avoiding light exposure of reagents. M.p.: $104-105^{\circ} \mathrm{C}$. Elemental analysis: Calcd. for $\mathrm{C}_{22} \mathrm{H}_{38} 0_{6} \mathrm{Mo}: \mathrm{C}, 53.44 \% ; \mathrm{H}, 7.75 \%$. Found: C, 53.63\%; H, $7.69 \%$. IR spectra (DRIFT): 938 (s) and $913(\mathrm{~s}) \mathrm{cm}^{-1}$. NMR spectra (ppm, $\mathrm{CDCl}_{3}$, TMS as reference): $1.07(\mathrm{~s}, 9 \mathrm{H}) ; 1.20(\mathrm{~s}, 9 \mathrm{H}) ; .5 .97(\mathrm{~s}, 2 \mathrm{H})$.

\section{Film deposition}

Due to its moderate volatility and to avoid condensation in the tubing and valve system, the precursor was heated in a small crucible inside the reactor by heating tapes and controlling its temperature with a thermocouple. The carrier flux was measured and controlled with an MKS mass flow controller and the pressure was measured with a capacitance manometer. The deposition was carried on until no precursor was left in the crucible. The polycrystalline Pt, Ti and stainless steel substrates were mirror-polished to $1 \mu \mathrm{m}$, rinsed with bidistilled water and washed with ethanol in an ultrasonic bath. The $\mathrm{Si}(100)$ wafer was etched with $10 \% \mathrm{HF}$, rinsed with bidistilled water and annealed in air at $500^{\circ} \mathrm{C}$ for $2 \mathrm{~h}$. The $\mathrm{SiO}_{2}$ substrate was simply washed in ethanol in an ultrasonic bath.

\section{Instrumentation}

A Perkin Elmer $\Phi 5600$ ci spectrometer with monochromatized $A l K_{\alpha}$ radiation (1486.6 eV) was used for the XPS analyses. The working pressure was less than $2 \times 10^{-7} \mathrm{~Pa}$. The spectrometer was calibrated by assuming the binding energy (BE) of the $\mathrm{Au} 4 \mathrm{f}_{7 / 2}$ line at $83.9 \mathrm{eV}$ with respect to the Fermi level. As an internal reference for the peak positions the $\mathrm{Cls}$ peak of hydrocarbon contamination has been assumed at $284.8 \mathrm{eV}$. The standard deviation in the BE values of the XPS lines is $0.10 \mathrm{eV}$. After a Shirley-type background subtraction, the raw spectra were fitted using a non-linear least-square fitting program adopting Gaussian-Lorentzian peak shapes for all the peaks. The atomic compositions were evaluated using sensitivity factors as provided by $\Phi$ V5.4A software. Depth profiles were carried out by $\mathrm{Ar}^{+}$ sputtering at $2.5 \mathrm{keV}, 0.4 \mu \mathrm{A} \mathrm{cm} \mathrm{cm}^{-2}$ beam current density with an argon partial pressure of $5 \times 10^{-6} \mathrm{~Pa}$.

The UPS spectra were recorded using a VG-ESCALAB MKII spectrometer. All samples were heated at $450^{\circ} \mathrm{C}$ for $2 \mathrm{~h}$ immediately before introduction in the spectrometer. The carbon contamination was checked before collecting the UPS spectra by XPS. No thermal treatment was necessary for the $\mathrm{MoO}_{3}$ single crystal. 
IR measurements were performed on FTIR Bruker IFS 66, the UV-Vis data were recorded on a Varian Spectrophotometer Cary 5E.

Thermogravimetric analysis of the precursor was performed on a Perkin Elmer Thermobalance TGS-2 in both oxygen and nitrogen flows with a heating rate of $20^{\circ} \mathrm{C} / \mathrm{min}$. SEM micrographs were obtained on a XL 40 La B99 scanning electron microscope.

$\mathrm{X}$-ray diffraction measurements were performed on a Philips MPD 1880 powder diffractometer with a monochromatized $\mathrm{CuK}_{\alpha}$ radiation in the Bragg-Brentano parafocusing geometry.

\section{RESULTS AND DISCUSSION}

We performed the film deposition in a simple cold wall reactor heating the substrate by a button heater. Good deposits were only obtained using $\mathrm{O}_{2}$ as transport and reactive gas. No film deposition was obtained using $\mathrm{Ar}$ as the transport gas and temperatures $\leq 450^{\circ} \mathrm{C}$. These facts are well in tune with the precursor properties investigated by TGA analysis. We recorded thermograms of the precursor in both $\mathrm{N}_{2}$ and $\mathrm{O}_{2}$ flows and identified the volatile pyrolysis products by real time FT-IR. Due to sublimation of the compound, interpretation of the TGA curves is difficult. However, by using a sufficiently high heating rate it is possible to reduce the weight loss by sublimation so that variation in the thermogram slope caused by decomposition processes, can be clearly distinguished. Two completely different decomposition paths can be identified. The first one, obtained in an $\mathrm{N}_{2}$ flow, corresponds to the presence of vapours of the unaltered complex and at higher temperatures $\left(\mathrm{ca} .30\left(0^{\circ} \mathrm{C}\right.\right.$ ) to the free protonated ligand $(\mathrm{Hdpm})$ and water vapour. The second one shows the presence of the free ligand mixed with $\mathrm{CO}_{2}$ at lower temperatures $\left(\mathrm{ca} .200^{\circ} \mathrm{C}\right)$ and, by further increasing the temperature, of unidentified decomposition products, $\mathrm{CO}$ and $\mathrm{H}_{2} \mathrm{O}$ vapours. These data indicate a remarkably high stability of the precursor in $\mathrm{N}_{2}$ atmosphere and its tendency to follow a decomposition path which always implies the loss of a protonated ligand. The main difference between pyrolysis in $\mathrm{N}_{2}$ and $\mathrm{O}_{2}$ is the temperature at which this process begins. It is obvious that $\mathrm{O}_{2}$ oxidises the Hdpm ligand and therefore greatly favours the decomposition process.

The parameters used to have good quality films are summarized in the table reported below.

\begin{tabular}{|l|l|}
\hline Precursor temperature & $85-90^{\circ} \mathrm{C}$ \\
\hline Substrate temperature & $380-4300^{\circ} \mathrm{C}$ \\
\hline Carrier gas & $02(6$ mbar $)$ \\
\hline Thermal treatment & $450^{\circ} \mathrm{C}$ in air for $6 \mathrm{~h}$ \\
\hline O2 flow & $400-500 \mathrm{sccm}$ \\
\hline
\end{tabular}

Table 1 Growth conditions of $\mathrm{MOO}_{3}$ thin films

We obtained deposits on different substrates like polycrystalline $\mathrm{Pt}$ and $\mathrm{Ti}, \mathrm{Si}(100), \mathrm{SiO}_{2}$ and stainless steel. In all cases the XPS data confirmed that the stoichiometry of the as deposited films can bc formulated as $\mathrm{Mo}_{x} \mathrm{O}_{y}$, with Mo in oxidation states ranging from IV to VI. These findings can be ascribed to a partial oxidation of the molecular fragment $\mathrm{MoO}_{2}$ generated by loss of the Hdpm ligands from the complex (see TGA analysis). In figure 1 the XPS Mo3d peak of a sample grown with a lower $\mathrm{O}_{2}$ partial pressure ( 2 mbar) shows a shoulder in the lower binding energy side which can be attributed to the presence of $\mathrm{Mo}$ in the lower oxidation states |5|. However the films obtained with different $\mathrm{O}_{2}$ partial

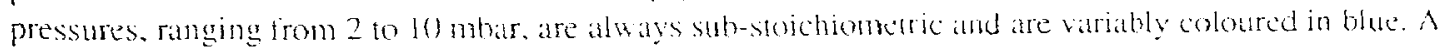


further annealing treatment in air $\left(450^{\circ} \mathrm{C}\right)$ produces pure transparent $\mathrm{MoO}_{3}$ films as checked by XPS, UV$V$ is and XRD analysis. The Mo3d peak is found at $232.7 \mathrm{eV}(F W H M=1.2 \mathrm{eV}$ ) and the $01 \mathrm{~s}$ at $530.5 \mathrm{eV}$ in agreement with the reported literature data [5]. According to the XPS data the average $O$ atomic fraction, found after thermal treatment, was $73.5 \%$ (75\% expected) so that all the samples appear to be slightly oxygen deficient. Depth profiles obtained from films grown on $\mathrm{Si}(100)$ and $\mathrm{Pt}$ show the carbon content is as low as $1 \%$ atomic fraction (figure 2). The UV-Vis spectra of an annealed sample deposited on $\mathrm{SiO}_{2}$ show an absorption with a maximum at $225 \mathrm{~nm}$ and a shoulder at 290 while no bands are found in the visible region of the spectrum up to $2000 \mathrm{~nm}$. These results agree with the absorption spectra of thin films of $\mathrm{MoO}_{3}$ deposited by vacuum evaporation followed by an annealing procedure in $\mathrm{O}_{2}$ at $300^{\circ} \mathrm{C}$ [6].

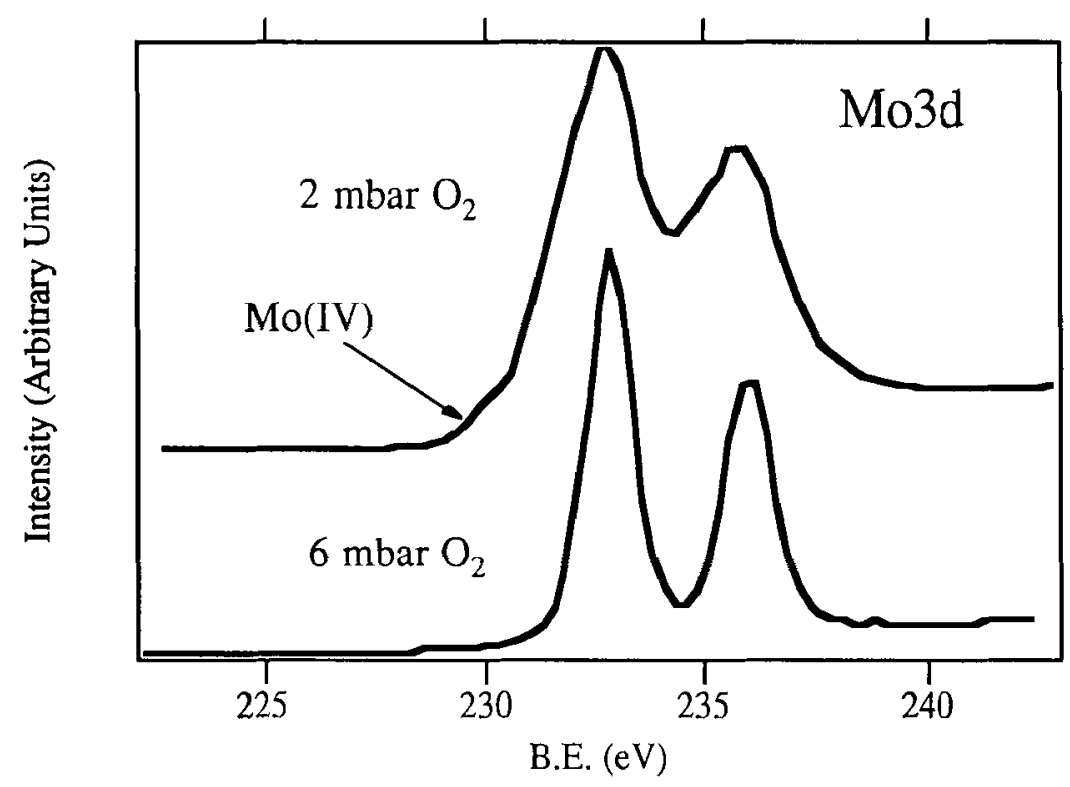

Figure 1: Mo3d peak of samples grown on $\mathrm{Si}(100)$ using different $\mathrm{O}_{2}$ pressures. Lower oxidation states of Mo are clearly detected when using a lower $\mathrm{O}_{2}$ pressure.

The XRD analysis confirms that the deposited films are crystalline and that a single molybdite phase is present independently from the adopted substrate. The XRD pattern of the films grown on polycrystalline $\mathrm{Pt}, \mathrm{Ti}$ and stainless steel is directly comparable with the that of a powder sample [7]. In the case of samples grown on oxidized $\mathrm{Si}(100)$ a pattern corresponding to crystals with preferential orientation along the c-axis is found, while in the case of samples grown on $\mathrm{SiO}_{2}$ the crystallites are all iso-oriented along this axis. The morphology of the films and the crystallite size can be correlated directly with the ease of decomposition of the precursor on the surface. A higher nucleation rate enhances the growth of small particles corresponding to very smooth and reflective films. Lower nucleation rates correspond to the formation of larger crystallites and less homogeneous and reflective films. 


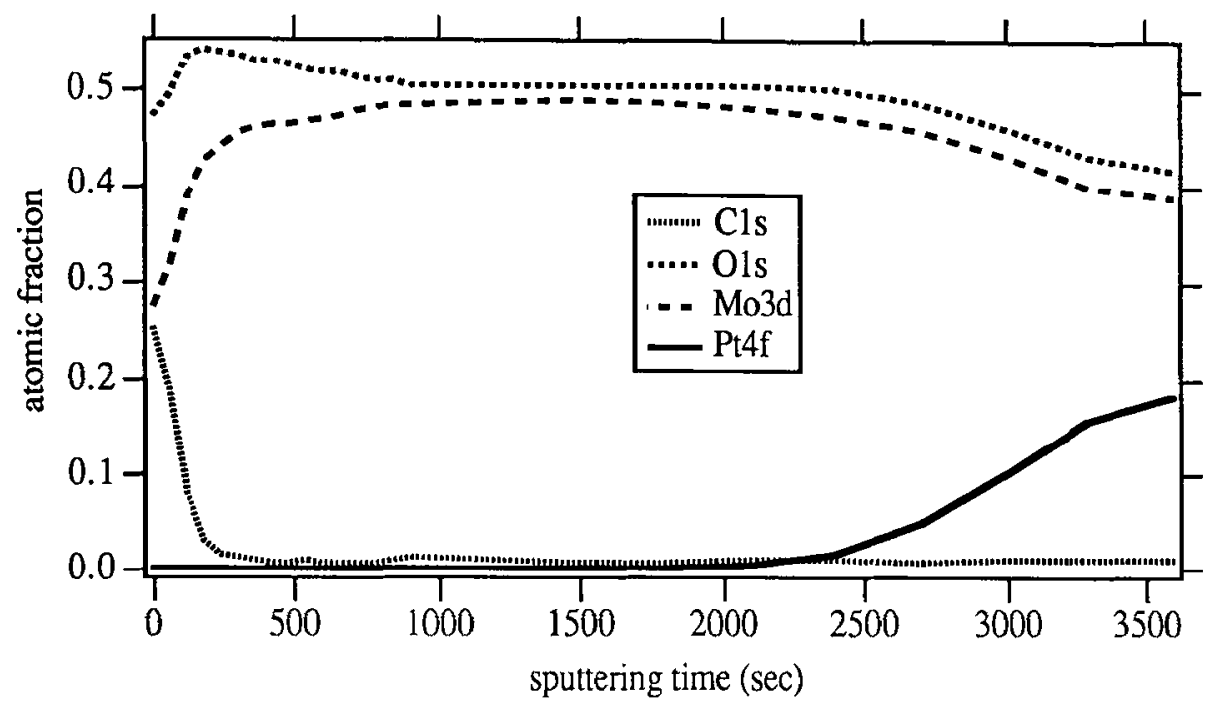

Figure 2: XPS depth profile obtained on a sample grown on Pt. The higher Mo atomic fraction with respect to $O$ is due to oxygen preferential sputtering.

As shown by the SEM micrographs (figure 3 ) the smaller particle size $(\approx 150 \mathrm{~nm})$ is found in case of films grown on $\mathrm{Ti}$ and to a less degree on stainless steel. Larger crystallites are found on Pt while in the case of surface oxidized $\mathrm{Si}(100)$ not only the particle size is larger, but also their shape is different. It seems clear that an oxidized surface increases the nucleation rate favouring the formation of smaller crystallites. In the case of $\mathrm{Pt}$ a lower nucleation rate is found so that larger crystallites can grow. This effect is caused by the twofold action of the reactive gas which firstly enhances the decomposition rate of the precursor by burning the Hdpm ligand, and secondly oxidizes the sub-stoichiometric $\mathrm{Mo}_{x} \mathrm{O}_{y}$ particles just formed. Actually a lower nucleation rate always corresponds to a less oxygen deficient film (only' slightly coloured in blue). A higher $\mathrm{O}_{2}$ flow enhances the precursor feed rate on the surface so that a higher nucleation rate is obtained, resulting in a smaller particle size. This behaviour is indeed found in the case of $\mathrm{Pt}$ so that smaller crystallites are formed whenever a higher $\mathrm{O}_{2}$ flow is used (see figure $3 \mathrm{C}$ and 3E).

In order to have information about the presence of oxygen defects in the deposited films we recorded the O2p XPS valence band for samples deposited on different substrates. In all cases the valence band is centered at a binding energy of about $7 \mathrm{eV}$ with two shoulders at about 5 and $9 \mathrm{eV}$. This is directly comparable with the valence band obtained for a $\mathrm{MoO}_{3}$ single crystal [8]. As can be clearly seen in figure 4 , a weak tail in the low binding energy side extends up to $0.5 \mathrm{eV}$. This tail is most probably due to the presence of oxygen defects in the films and can be assigned to a partial occupation of the Mo4d band according to the results of calculations performed on a cluster of formula $\mathrm{Mo}_{6} \mathrm{O}_{24}{ }^{14-}$ where the anion vacancy corresponds to either a two-coordinate or three-coordinate oxygen atom [9]. As pointed out by other authors the partial occupation of the $4 \mathrm{~d}$ band, which corresponds to the creation of $\mathrm{Mo}(\mathrm{V})$ colour centers on the surface of the film, might be caused by prolonged $x$-ray irradiation [10]. This effect is most probably associated to the intrinsic defective structure of the deposited films since it does not appear, in the same experimental conditions, in the case of the $\mathrm{MoO}_{3}$ single crystal (grown along c-axis). It is worth to point out that in all cases, according to the XPS data, the films were found to be slightly oxygen deficient. 

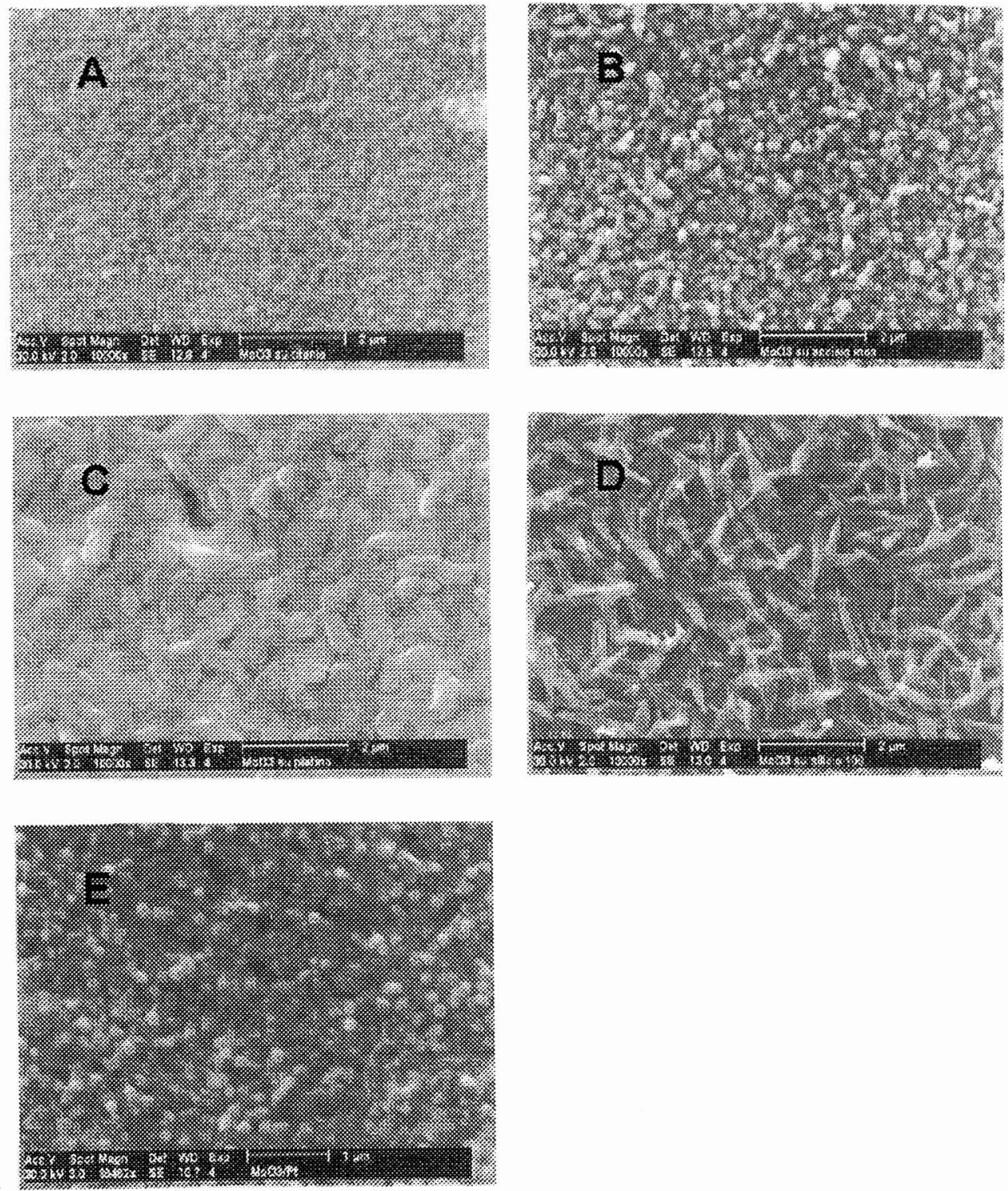

Figure 3: SEM micrographs of $\mathrm{MoO}_{3}$ films deposited on: A) Ti, B) stainless steel, C) Pt (400 sccm), D) Si(100), E) Pt $(490 \mathrm{sccm})$ 


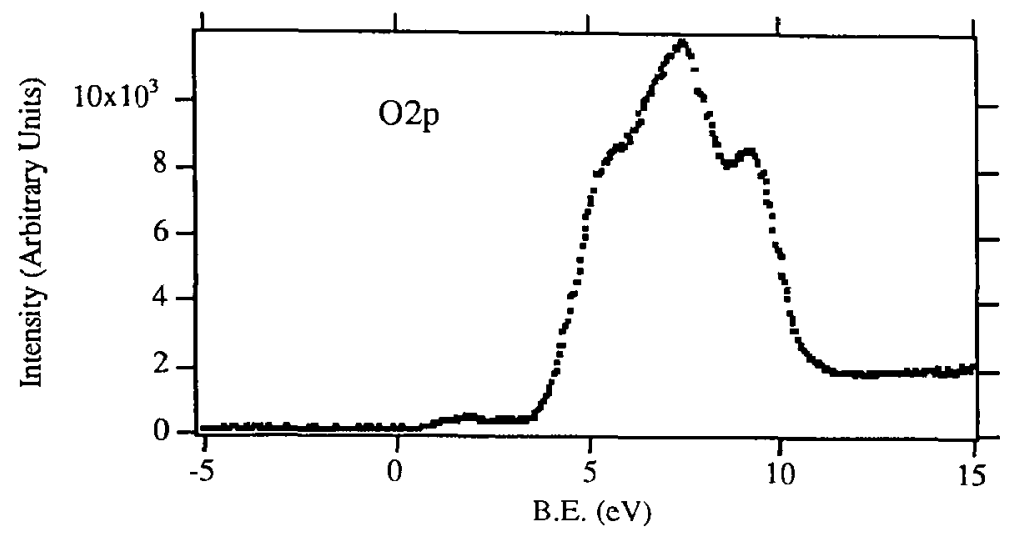

Figure 4: XPS valence band obtained on a sample grown on $\mathrm{Si}(100)$.

The UPS HeI valence band spectra recorded for a $\mathrm{MoO}_{3}$ single crystal, a film deposited on stainless steel and on $\mathrm{SiO}_{2}$ are reported in figure 5. The three curves are aligned with respect to the strong peak centred at about $7 \mathrm{eV}$. The valence band shapes of the single crystal and the film deposited on $\mathrm{SiO}_{2}$ are quite similar in the range between 18 and $10 \mathrm{eV}$. On the contrary, a quite remarkable difference is found in the curvature of the HeI valence band of the film deposited on stainless steel (similar results were obtained for a sample grown on $\mathrm{Ti}$ ). Both samples grown on stainless steel and $\mathrm{SiO}_{2}$ show strong electron emission in the low kinetic energy side of the spectrum. On the contrary the single crystal, does not show this feature that can be clearly seen only after a mild sputtering with $\mathrm{Ar}^{+}$ions. This confirms the hypotheses that in these metal-oxide systems a high number of defects and vacancies plays an important role in the photoemission properties. In summary polycrystalline samples present a significantly different valence band with respect to a single crystal. This fact is probably to be ascribed to the difective structure of the material. These strong differences are somehow less pronounced in the iso-oriented film grown on $\mathrm{SiO}_{2}$.

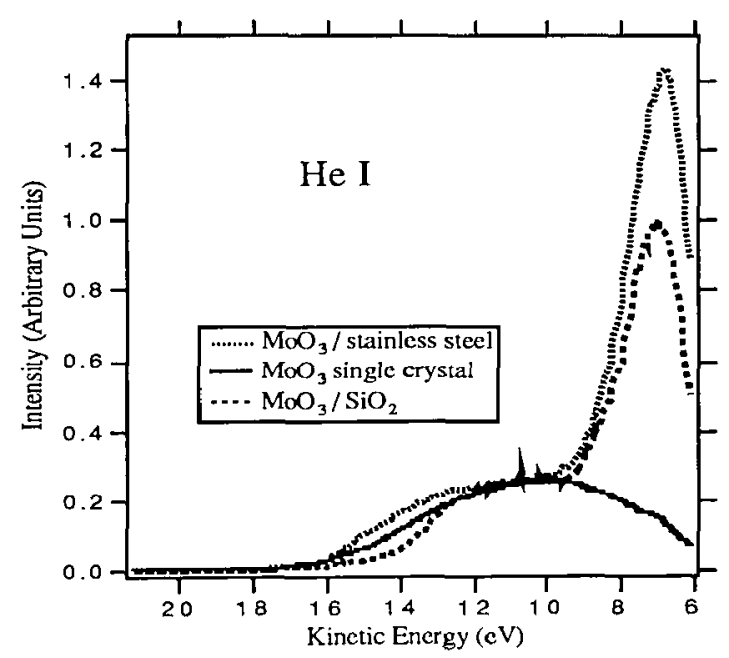

Figure 5: HeI valence bands of films deposited on stainless steel and $\mathrm{SiO}_{2}$ compared with the valence bands of a $\mathrm{MoO}_{3}$ single crystal (c axis perpendicular to the surface) 


\section{CONCLUSIONS}

The molybdenyl complex $\mathrm{MoO}_{2}(\mathrm{dpm})_{2}$ was found to be a suitable precursor in the MOCVD of $\mathrm{MoO}_{3}$ films. The compound can be easily synthetized and manipulated. As expected, the crystalline films obtained show a very low degree of carbon contamination. Interdiffusion phenomena with reactive substrates such as Si are prevented by the deposition of already oxidized Mo species. Different substrates have strong influence on nucleation rate, crystallinity, and surface morphology. According to our experiments, the film growth rate is feed limited. Freshly oxidized surfaces favour the nucleation rate of $\mathrm{Mo}_{\mathrm{x}} \mathrm{O}_{\mathrm{y}}$ particles. Photoemission measurements indicate the presence of oxygen vacancies in the deposited films. These defects can be increased by $x$-ray or UV irradiation owing to an intrinsic lower stability of polycrystalline films with respect to the single crystal. In agreement with XRD data, the film deposited on $\mathrm{SiO}_{2}$ is certainly more ordered and roughly recalls the electronic properties of the $\mathrm{MoO}_{3}$ single crystal.

\section{Acknowledgements}

The authors thank prof. G. Favero for the TGA measurements, prof. F. Parmigiani for providing $\mathrm{MoO}_{3}$ single crystals and prof. G. Bandoli for the XRD measurements.

This work was partly supported by the Ministero per l'Università e la Ricerca Scientifica e Tecnologica (MURST).

\section{REFERENCES}

[1] A. Donnadieu, D. Davazoglou and A. Abdellaoui, Thin Solid Films, 164 (1988) 333.

[2] T. Kodas, M. Hampden Smith, The Chemistry of metal CVD, (VCH Weinheim - New York - Basel Cambridge - Tokyo, 1994) p. 390 and refences therein.

[3] S.J. Lippard, Progress in Inorganic Chemistry - Vol 22 (J. Wiley Interscience, New York - London Sydney - Toronto 1977) pp. 26 - 29.

[4] W. Schröter, Materials Science and Technology - Vol. 4 - Electronic Structure and Properties of Semiconductors ( R.W. Cahn, P. Haansen, E.J. Kramer - VCH Weinheim - New York - Basel Cambridge 1991), pp 422-438.

[5] B. Brox and I. Olefjord, Surf and Interf. Anal., 13 (1988) 3.

[6] S.K. Deb and J.A. Chopoorian, J. Appl. Phys., 37 (1966) 4818.

[7] Pattern 35 - 609 on JCPDS - ICDD (Joint Commitee on Powder Diffraction Standards - International Center for Diffraction Data).

[8] F. Parmigiani unpublished results

[9] R. K. Grasselli and M. Tenhover, Surf. Sci., 134 (1983) 237.

[10] R.J. Colton, A.M. Guzman, J.W. Rabalais, J. Appl. Phys., 49 (1978) 409. 